\title{
Target blood pressure management during cardiopulmonary bypass improves lactate levels after cardiac surgery: a randomized controlled trial
}

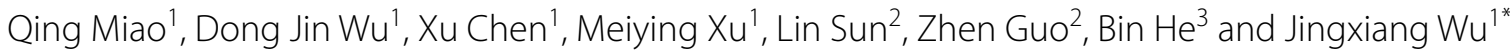

\begin{abstract}
Background: Hyperlactatemia is associated with a poor prognosis in cardiac surgery patients. This study explored the impact of target blood pressure management during cardiopulmonary bypass (CPB) on blood lactate levels after cardiac surgery.

Methods: Adult patients undergoing cardiac valve surgery between 20/1/2020 and 30/6/2020 at Shanghai Chest Hospital were enrolled. The patients were randomized into a low mean arterial pressure (L-MAP) group (target MAP between 50 and $60 \mathrm{mmHg}$ ) or a high mean arterial pressure (H-MAP) group (target MAP between 70 and $80 \mathrm{mmHg}$ ), $n=20$ for each. Norepinephrine was titrated only during CPB to maintain MAP at the target level. Blood lactate levels in the two groups were detected before the operation (T0), at the end of CPB (T1), at the end of the operation (T2), $1 \mathrm{~h}$ after the operation (T3), $6 \mathrm{~h}$ after the operation (T4) and $24 \mathrm{~h}$ after the operation (T5). The primary outcome was the blood lactate level at the end of the operation (T2). The secondary outcomes included the blood lactate level at T1, $\mathrm{T} 3, \mathrm{~T} 4$, and $\mathrm{T} 5$ and the dose of epinephrine and dopamine within $24 \mathrm{~h}$ after the operation, time to extubation, length of stay in the ICU, incidence of readmission within 30 days, and mortality within 1 year.
\end{abstract}

Results: Forty patents were enrolled and analyzed in the study. The lactate level in the H-MAP group was significantly lower than that in the L-MAP group at the end of the operation (3.1 [IQR 2.1, 5.0] vs. 2.1 [IQR 1.7, 2.9], $P=0.008$ ) and at the end of CPB and 1 hour after surgery. The dose of epinephrine within $24 \mathrm{~h}$ after the operation, time to extubation and length of stay in the ICU in the L-MAP group were significantly higher than those in the H-MAP group.

Conclusions: Maintaining a relatively higher MAP during CPB deceased the blood lactate level at the end of surgery, reduced epinephrine consumption, and shortened the time to extubation and length of stay in the ICU after surgery.

Trial registration: This single-center, prospective, $\mathrm{RCT}$ has completed the registration of the Chinese Clinical Trial Center at 8/1/2020 with the registration number ChiCTR2000028941. It was conducted from 20/1/2020 to 30/6/2020 as a single, blinded trial in Shanghai Chest Hospital.

Keywords: Target blood pressure, Cardiopulmonary bypass, Mean arterial pressure, Lactate, Cardiac surgery

*Correspondence: wjx1132@163.com

1 Department of Anesthesiology, Shanghai Chest Hospital, Shanghai Jiao Tong University, No. 241 West Huaihai Road, Shanghai 200030, China

Full list of author information is available at the end of the article

\section{Background}

Hyperlactatemia usually occurs after cardiac surgery, which is related to poor prognosis $[1,2]$ and is reported to be an independent risk factor for postoperative mortality in cardiac surgery patients [3]. Therefore, alleviating original author(s) and the source, provide a link to the Creative Commons licence, and indicate if changes were made. The images or other third party material in this article are included in the article's Creative Commons licence, unless indicated otherwise in a credit line to the material. If material is not included in the article's Creative Commons licence and your intended use is not permitted by statutory regulation or exceeds the permitted use, you will need to obtain permission directly from the copyright holder. To view a copy of this licence, visit http://creativecommons.org/licenses/by/4.0/. The Creative Commons Public Domain Dedication waiver (http://creativeco mmons.org/publicdomain/zero/1.0/) applies to the data made available in this article, unless otherwise stated in a credit line to the data. 
postoperative hyperlacticaemia is vitally important for improving the prognosis of cardiac patients [4].

Blood flow has a pulsatile characteristic in normal heart activities. However, nonphysiological advection perfusion is adopted during cardiopulmonary bypass (CPB) in many heart centers. Unlike advection perfusion, which provides kinetic energy to normalize blood flow, pulsatile perfusion reduces the potential energy under the same mean arterial pressure (MAP), resulting in decreased blood flow in capillaries and microcirculation perfusion. Thus, we supposed that a relatively high MAP during CPB may benefit microcirculation perfusion in reducing blood lactate levels, which is a sensitive indicator of poor microcirculation perfusion. Based on the Guidelines for CPB in 2019 European Adult Cardiac Surgery [5], it is safe to maintain the MAP between 50 and $80 \mathrm{mmHg}$ during $\mathrm{CPB}$. However, in clinical practice, we observed a clinical phenomenon in which a relatively higher MAP within the recommended range during $\mathrm{CPB}$ seemed to be correlated with a lower postoperative blood lactate level. To verify this phenomenon, we conducted a randomized controlled trial (RCT) to test the primary hypothesis that mean arterial pressure maintained at $70-80 \mathrm{mmHg}$ by norepinephrine titration [6] during $\mathrm{CPB}$ could reduce the lactate level after cardiac surgery and improve the early recovery of patients.

\section{Methods}

\section{Clinical data}

This single-center, prospective, RCT study was conducted in accordance with the Declaration of Helsinki tenets and the Basel, and approved by the Shanghai Chest Hospital of Shanghai Jiaotong University research ethics board (KS1960) at 31/10/2019 and registered at the Chinese Clinical Trial Center on 8/1/2020 with registration number ChiCTR2000028941. This study was performed by adhering to the Consolidated Standards of Reporting Trials (CONSORT) statement. Forty patients who were scheduled for cardiac valve surgery in the Cardiovascular Surgery Department of Shanghai Chest Hospital (Shanghai, China) from 20/1/2020 to 30/6/2020 were enrolled in the study. All enrolled patients signed their informed consent without knowing their groups. The inclusion criteria were patients older than 18 years with a New York Heart Association Class (NYHAC) level II-III, blood lactate level $<1.6 \mathrm{mM} \bullet \mathrm{L}^{-1}$, alanine aminotransferase $($ ALT $)<50 \mathrm{U} \cdot \mathrm{L}^{-1}$, creatinine $(\mathrm{Cr})<111 \mathrm{uM} \cdot \mathrm{L}^{-1}$, blood urea nitrogen $(\mathrm{BUN})<9.5 \mathrm{mM} \cdot \mathrm{L}^{-1}$, and brain natriuretic peptide $(B N P)<100 \mathrm{pg} \cdot \mathrm{ml}^{-1}$ who required observation in the intense care unit (ICU) after surgery. The ICU researchers were blinded to the group assignments. The exclusion criteria were patients who underwent reoperation within $24 \mathrm{~h}$ after the initial operation due to surgical factors.

\section{Interventions and measurements}

The enrolled patients were randomized into a low mean arterial pressure (L-MAP) group (target MAP between 50 and $60 \mathrm{mmHg}$ ) and a high mean arterial pressure (H-MAP) group (target MAP between 70 and $80 \mathrm{mmHg}$ ) based on the random numbers generated by EXCEL software in a 1:1 ratio. The randomization sequence was generated by staff not otherwise involved in the current study. MAP in the L-MAP group was maintained in the range of $50-60 \mathrm{mmHg}$ according to the clinical experience of the anesthesiologist. A bolus of phenylephrine (0.25-0.5 mg per injection, maximum dose $<2 \mathrm{mg}$ ) was given when the MAP was under $50 \mathrm{mmHg}$. Infusion of nitroglycerin $(0.2 \sim 4 \mu \mathrm{g} / \mathrm{kg} / \mathrm{min})$ was started when the MAP was over $60 \mathrm{mmHg}$ during CPB. MAP was managed at a target of $70-80 \mathrm{mmHg}$ in the H-MAP group by norepinephrine titration [initial rate: $0.03 \sim 0.1 \mu \mathrm{g} /$ $\mathrm{kg} / \mathrm{min}$, maximum rate: $0.4 \mu \mathrm{g} \bullet(\mathrm{kg} \bullet \mathrm{min})^{-1}$ ] during CPB. MAP was continuously measured every $15 \mathrm{~min}$ and used for analysis in both study groups. The area under or upper the curve (AUC) out of the target blood pressure range was calculated as previously described [7]. MAP was maintained over $65 \mathrm{mmHg}$ postoperatively in both groups. Norepinephrine $(0.03 \sim 0.1 \mu \mathrm{g} / \mathrm{kg} / \mathrm{min})$, nitroglycerin $(0.2 \sim 4 \mu \mathrm{g} / \mathrm{kg} / \mathrm{min})$, epinephrine $(0.03 \sim 0.1 \mu \mathrm{g} / \mathrm{kg} /$ $\mathrm{min})$ and dopamine $(3 \sim 10 \mu \mathrm{g} / \mathrm{kg} / \mathrm{min})$ were used if necessary according to clinical experience or routine clinical practice after the operation. The blood lactate level in the two groups was measured before the operation (T0), at the end of CPB (T1), at the end of the operation (T2), $1 \mathrm{~h}$ after the operation (T3), $6 \mathrm{~h}$ after the operation (T4) and $24 \mathrm{~h}$ after the operation (T5). The cumulative dosage of the anesthetic and vasoactive drugs, heart rate (HR), hematocrit (HCT), blood glucose, Cr, and BUN in the perioperative period, duration of surgery, duration of aortic occlusion, duration of $\mathrm{CPB}$, time to the end of surgery after weaning from $\mathrm{CPB}$, time to extubation, length of stay in the ICU, incidence of readmission within 30 days and one-year all-cause mortality were recorded and compared.

\section{Anesthesia and CPB}

Patients in the two groups were treated with the same protocol anesthesia method and CPB management. Radial arterial cannulation and arterial blood gas analysis were carried out before anesthesia induction. General anesthesia was induced with $0.8 \mu \mathrm{g} \cdot \mathrm{kg}^{-1}$ sufentanil, $0.12 \mathrm{mg} \cdot \mathrm{kg}^{-1}$ midazolam, $2 \mathrm{mg} \cdot \mathrm{kg}^{-1}$ propofol and $0.15 \mathrm{mg} \cdot \mathrm{kg}^{-1}$ cis-atracurium intravenously. Drugs were target controlled and infused with propofol in 
$4-8 \mathrm{mg} \bullet(\mathrm{kg} \bullet \mathrm{h})^{-1}$, remifentanil in $0.1-0.15 \mu \mathrm{g} \bullet(\mathrm{kg} \bullet \mathrm{h})^{-1}$ and cis-atracurium in $0.1-0.3 \mathrm{mg} \bullet(\mathrm{kg} \cdot \mathrm{h})^{-1}$ in the maintenance period. All anesthetic medications were stopped at the end of the surgery. All patients underwent $\mathrm{CPB}$ based on the Guidelines for CPB in 2019 European Adult Cardiac Surgery [5]. After splitting the sternum, CPB was established through the ascending aorta and superior and inferior vena cava. Cardioplegia was perfused through the aortic root or coronary opening. CPB was prefilled with $1000 \mathrm{ml}$ hydroxyethyl starch and $500 \mathrm{ml}$ lactated Ringer. CPB started after systemic heparinization and $\mathrm{ACT}>480 \mathrm{~s}$. Both groups were on occlusive $\mathrm{CPB}$. The perfusion flow was maintained at $2.4 \mathrm{~L} \cdot \mathrm{min}^{-1} \cdot \mathrm{m}^{-2}$, and the mixed venous blood oxygen saturation was maintained above $75 \%$ under mild hypothermia conditions. Intraoperative blood glucose was controlled to $8 \mathrm{mM} \cdot \mathrm{L}^{-1}$ by insulin infusion. The ascending aorta was crossclamped followed by warm blood cardioplegia perfusion through the aortic root or coronary opening when the nasopharyngeal temperature was $32-34^{\circ} \mathrm{C}$. After the operation, rewarming, ascending aorta recovery, cardiac rebeating and auxiliary circulation were carried out until hemodynamics became stable and the nasopharyngeal temperature reached $36.8^{\circ} \mathrm{C}$. CPB was stopped, and protamine was injected to neutralize heparin. The patient was sent to the ICU for observation after surgery.

\section{Study endpoints}

The primary outcome was the blood lactate level at the end of surgery (T2). The secondary outcomes were blood lactate levels at the end of CPB (T1), T3, T4, and T5; dose of epinephrine and dopamine within $24 \mathrm{~h}$ after surgery; time to extubation; length of stay in the ICU; readmission within 30 days; and mortality within 1 year.

\section{Statistical analysis}

Continuous variables including age, body mass index (BMI), left ventricular ejection fraction (LVEF), clinical data and blood lactate levels are presented as the mean \pm standard deviation (SD), median [first quartile, third quartile] or $\mathrm{N}$ (N/total number of patients\%). Kolmogorov-Smirnov tests were used to assess the distribution of continuous variables. Normally distributed variables were analyzed using Student's t test; otherwise, nonnormally distributed variables were analyzed using Mann-Whitney U-tests. Classified variables, including sex, ASA classification, hypertension, diabetes prevalence, NYHAC and surgical type, were recorded as numbers or percentages. Categorical variables were compared using a chi-square test or Fisher's exact test as appropriate.

The blood lactate level and MAP at multiple time points were analyzed with ANOVA for repeated measures and least significant difference post hoc testing. $P<0.05$ (2-sided) was considered statistically significant. We estimated the effect of continuous monitoring on the area under or upper the curve (AUC) out of target blood pressure using the 2-sample Wilcoxon rank-sum test and Hodges Lehmann estimation of location shift with the corresponding asymptotic $95 \%$ CI. The balance of baseline and surgical characteristics was compared using absolute standardized difference scores (ASDs) as previously described [8]. Imbalance was defined as ASD (Cohen's d) greater than 0.20 (small effect size), 0.5 (median effect size) and 0.8 (large effect size). Considering that the sample size of the current study was small, ASD $>0.50$ was selected as an indication of potential confounding and to adjust for such factors directly in the analyses comparing the groups on the outcome.

\section{Sample size calculation}

The sample size was calculated based on our pre-experimental results. The lactate level in the H-MAP group was $2.46 \pm 1.13 \mathrm{mM} \cdot \mathrm{L}^{-1}$ vs. $3.68 \pm 1.16 \mathrm{mM} \cdot \mathrm{L}^{-1}$ in the L-MAP group at the end of the operation. It was calculated that 20 cases for each group were needed based on $\alpha=0.05$ and $\beta=0.1$ using a two-sided two-sample unequal-variance $\mathrm{t}$ test.

\section{Results}

\section{Baseline characteristics}

The basic characteristics of the enrolled patients are summarized in Table 1. There were no significant differences in age, sex, BMI, ASA classification, hypertension, diabetes prevalence, LVEF NYHAC classification, or surgical type. Between the two groups.

The MAPs during CPB are shown in Fig. 1. Figure 1a is a box \& whiskers plot with $10-90$ percentile of the median MAP during CPB of the two groups. The median MAP in each group was successfully maintained in their target blood pressure range $(57 \mathrm{mmHg}$ in L-MAP vs. $76 \mathrm{mmHg}$ in H-MAP). Figure 1b. shows the AUC out of the target MAP. There was no significant difference between the two groups.

\section{Blood lactate level}

As shown in Fig. 2, the lactate level in the H-MAP group was significantly lower than that in the L-MAP group at the end of surgery. The lactate levels of the two groups began to show differences from the end of CPB until 1 hour after surgery. After reaching the peak at $6 \mathrm{~h}$ after the operation, the lactate level began to drop, but there were no differences between the two groups (Fig. 2b). The primary outcome was the blood lactate level at the end of surgery (T2), presented in Fig. 2a as a box \& whiskers plot with min to max, showing all points. 
Table 1 Baseline characteristics of the patients

\begin{tabular}{|c|c|c|c|}
\hline Characteristics & L-MAP Group $(n=20)$ & H-MAP Group $(n=20)$ & $\mathrm{ASD}^{\mathrm{a}}$ \\
\hline Age (yr) & $61[45,68]$ & $63[53,69]$ & 0.12 \\
\hline $\operatorname{Sex}(M / F)$ & $12 / 8$ & $8 / 12$ & 0.45 \\
\hline $\mathrm{BMI}\left(\mathrm{kg} \cdot \mathrm{m}^{-2}\right)$ & $25.4[20.0,26.4]$ & $21.9[20.6,26.4]$ & 0.16 \\
\hline ASA (I/III) & $5 / 15$ & $3 / 17$ & 0.35 \\
\hline Hypertension, n (\%) & $7(35)$ & $8(40)$ & 0.12 \\
\hline Diabetes prevalence, n (\%) & $1(5)$ & $1(5)$ & 0.00 \\
\hline LVEF (\%) & $60[50,63]$ & $63[61,65]$ & 0.44 \\
\hline NYHAC (I/IIII) & $7 / 13$ & $12 / 8$ & 0.56 \\
\hline Surgical types, n (\%) & & & 0.12 \\
\hline AVR & $1(5)$ & $5(25)$ & \\
\hline AVP & $2(10)$ & $1(5)$ & \\
\hline MVR & $3(15)$ & $1(5)$ & \\
\hline MVP & $2(10)$ & $1(5)$ & \\
\hline TVP & $0(0)$ & $2(10)$ & \\
\hline $\mathrm{AVP}+\mathrm{MVP}$ & $2(10)$ & $0(0)$ & \\
\hline$A V R+M V R+T V P$ & $0(0)$ & $2(10)$ & \\
\hline$A V R+M V P+T V P$ & $4(20)$ & $2(10)$ & \\
\hline$M V R+T V P$ & $5(25)$ & $1(5)$ & \\
\hline $\mathrm{MVP}+\mathrm{TVP}$ & $1(5)$ & $5(25)$ & \\
\hline Operation time (min) & $270[240,300]$ & $260[210,280]$ & 0.55 \\
\hline Aortic occlusion time (min) & $90[82,127]$ & $110[80,132]$ & 0.19 \\
\hline CPB time (min) & $140[120,160]$ & $150[110,170]$ & 0.07 \\
\hline Post CPB time (min) & $84[63,95]$ & $70[64,76]$ & 0.51 \\
\hline
\end{tabular}

Abbreviations: MAP Mean arterial pressure, BMI Body mass index, ASA American Society of Anesthesiologists, LVEF Left ventricular ejection fraction, NYHAC New York Heart Association. AVR Aortic valve replacement, AVP Aortic valvuloplasty, MVR Mitral valve replacement, MVP Mitral valvuloplasty, TVP Tricuspid valvuloplasty. ${ }^{\mathrm{a} A S D}$ Absolute standardized difference $=$ difference in means or proportions divided by the standard error; imbalance defined as an absolute value greater than 0.20 (small effect size), 0.5 (median effect size) and 0.8 (large effect size)
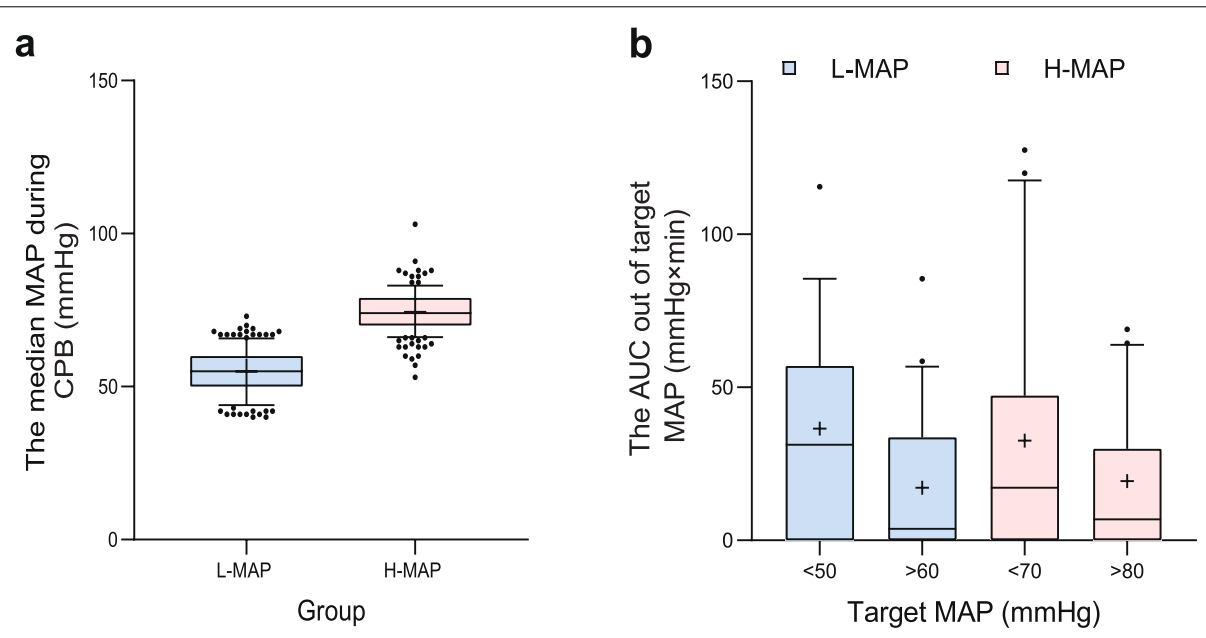

Fig. 1 The median MAP and the time out of the target MAP during CPB

\section{Clinical data}

As shown in Table 2, there were no statistically significant differences between the two groups in parameters such as $\mathrm{HR}$, HCT, blood glucose, Cr, perioperative BUN, duration of surgery, duration of aortic occlusion, $\mathrm{CPB}$ and time to the end of surgery after weaning from $\mathrm{CPB}$, 

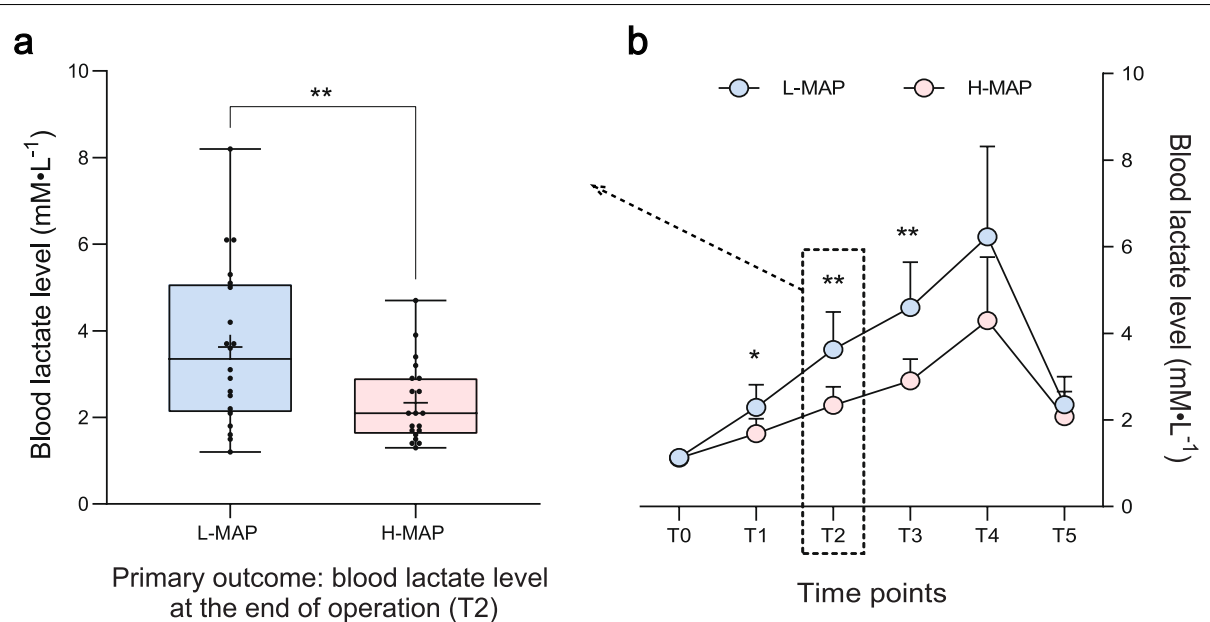

Fig. 2 Blood lactate level. ${ }^{*}$ Statistically significant $\left.\left({ }^{*} P<0.05{ }^{*} P<0.01\right)\right)$. Abbreviations: MAP: mean arterial pressure. T0 = before the operation; $\mathrm{T} 1=$ at the end of $\mathrm{CPB}, \mathrm{T} 2=$ at the end of the operation, $\mathrm{T} 3=1 \mathrm{~h}$ after the operation, $\mathrm{T} 4=6 \mathrm{~h}$ after the operation, $\mathrm{T} 5=24 \mathrm{~h}$ after the operation

readmission rate within 30 days, and mortality within 1 year. There was also no significant difference in anesthetic and vasopressor usage between the two groups. The cumulative postoperative epinephrine administered within $24 \mathrm{~h}$, the time of extubation and the length of stay in the ICU in the L-MAP group were significantly higher than those in the H-MAP group.

\section{Discussion}

The cause of hyperlactacidemia falls into two types: insufficient perfusion or hypoxia of the tissue, such as shock or ischemia [4], and activation of the pyruvate replacement pathway due to underlying diseases, such as liver diseases, malignant tumors, or mitochondrial myopathy [9]. Insufficient perfusion or hypoxia occurs widely during $\mathrm{CPB}$ after cardiac surgery, which forms the focus of this study. Most currently available guidelines for the treatment of severe septic shock patients recommend the use of norepinephrine to increase MAP above $65 \mathrm{mmHg}$ when the volume therapy loses effectiveness, which is believed to be beneficial to improving circulatory perfusion and lactic acidosis [10]. Therefore, sufficient MAP is the main controllable factor to ensure microcirculation perfusion. It is common knowledge that the lactate level directly reflects the perfusion condition and is closely related to the prognosis of patients. Thus, we hypothesized that organ perfusion could be improved by appropriately adjusting MAP during $\mathrm{CPB}$, although the perfusion flow is constant.

In this study, we observed the impact of targeted blood pressure management during CPB on lactate levels after cardiac surgery and found that the blood lactate level in the H-MAP group was significantly lower than that in the
L-MAP group at the end of surgery and $1 \mathrm{~h}$ after surgery, suggesting that maintaining a relatively higher perfusion pressure (MAP $70-80 \mathrm{mmHg}$ ) during $\mathrm{CPB}$ was more conducive to improving the perfusion and oxygen supply to reduce lactate levels after surgery. This conclusion was further confirmed by the shortened time of extubation, reduced length of ICU stay, and use of less epinephrine for circulation support $24 \mathrm{~h}$ after the operation in the H-MAP group.

In addition, MAP before anesthesia induction showed no significant difference between the two groups. Although studies have shown that blood pressure before anesthesia induction does not reflect the actual blood pressure of patients [11], maintaining the MAP close to the level before anesthesia induction during $\mathrm{CPB}$ will benefit patients. Knowing that hyperlactacidemia during CPB is closely related to postoperative mortality in cardiac surgery, it is important to redress the risk factors for hyperlactacidemia [12], which is defined as a perioperative blood lactate level above $3 \mathrm{mM} \cdot \mathrm{L}^{-} 1$ [13]. In both groups, blood lactate reached the level of hyperlactacidemia at the end of surgery and at $6 \mathrm{~h}$ after surgery. The lactate level in the H-MAP group was significantly lower than that in the L-MAP group. Similar results were shown in the study of Siepe [14], but their target MAP was $80-90 \mathrm{mmHg}$ for $\mathrm{H}-\mathrm{MAP}$ vs. $60-70 \mathrm{mmHg}$ for L-MAP, which was higher than that in our study. GOLD believed that a higher MAP $(80-100 \mathrm{mmHg})$ during $\mathrm{CPB}$ was safe and effectively improved outcomes after coronary bypass [15]. However, in Vedel's study, it was reported that a low level of MAP does not modify lactate during cardiac surgery [6], but the operation time, bypass time, and cross clamp time were all shorter than 
Table 2 Perioperative clinical data

\begin{tabular}{|c|c|c|c|}
\hline Clinical Data & L-MAP Group $(n=20)$ & H-MAP Group $(n=20)$ & $P$ Value \\
\hline \multicolumn{4}{|l|}{ Hemodynamics parameter } \\
\hline \multicolumn{4}{|l|}{$\mathrm{HR}(\mathrm{bpm})$} \\
\hline baseline & $79[72,86]$ & $81[75,85]$ & 0.321 \\
\hline 30 min post $C P B$ & $88[78,92]$ & $87[83,90]$ & 0.827 \\
\hline at the end of the operation & $90[83,97]$ & $87[80,98]$ & 0.147 \\
\hline \multicolumn{4}{|l|}{$\mathrm{MAP}(\mathrm{mmHg})$} \\
\hline before induction & $87[73,98]$ & $92[83,110]$ & 0.698 \\
\hline 30 min post $C P B$ & $67[60,70]$ & $70[68,73]$ & 0.697 \\
\hline end of the operation & $67[63,77]$ & $70[63,73]$ & 0.638 \\
\hline $1 \mathrm{~h}$ after the operation & $68[60,76]$ & $71[68,77]$ & 0.072 \\
\hline $6 \mathrm{~h}$ after the operation & $71[70,79]$ & $68[64,72]$ & 0.543 \\
\hline $24 \mathrm{~h}$ after the operation & $75[70,79]$ & $70[61,75]$ & 0.646 \\
\hline \multicolumn{4}{|l|}{ Perioperative medications } \\
\hline \multicolumn{4}{|l|}{ Anesthetics } \\
\hline Propofol (mg) & $2683.2[2080,2878.4]$ & $2142.4[1820,2534.4]$ & 0.457 \\
\hline Sufentanil $(\mu \mathrm{g})$ & $56.2[48,63.4]$ & $52.8[49.4,63.4]$ & 0.607 \\
\hline Midazolam (mg) & $8.4[7.2,9.5]$ & $7.9[7.4,9.5]$ & 0.521 \\
\hline Cis-atracurium (mg) & $67.1[52,72]$ & $58.6[45.5,79.1]$ & 0.472 \\
\hline Remifentanil $(\mu \mathrm{g})$ & $33.5[26,36]$ & $29.3[22.8,39.6]$ & 0.416 \\
\hline \multicolumn{4}{|l|}{ Vasopressor drugs } \\
\hline Phenylephrine during CPB (mg) & $0.35[0.15,0.48]$ & $0.4[0.3,0.52]$ & 0.854 \\
\hline Norepinephrine during CPB (mg) & $0.17[0,0.19]$ & $0.72[0.47,0.95]$ & $0.000^{* * *}$ \\
\hline Epinephrine within $24 \mathrm{~h}$ after the operation (mg) & $0.72[0,1.8]$ & $0[0,0]$ & $0.024^{*}$ \\
\hline Dopamine within $24 \mathrm{~h}$ after the operation (mg) & $314[0,420]$ & $0[0,300]$ & 0.088 \\
\hline \multicolumn{4}{|l|}{ Vasodilator drugs } \\
\hline Nitroglycerin during CPB (mg) & $1.4[0,2.1]$ & $0[0,2.2]$ & $0.000^{* * *}$ \\
\hline Nitroglycerin within $24 \mathrm{~h}$ after the operation (mg) & $0[0,0.5]$ & $0[0,0.7]$ & 0.243 \\
\hline \multicolumn{4}{|l|}{ Laboratory parameters } \\
\hline \multicolumn{4}{|l|}{ HCT (\%) } \\
\hline during $C P B$ & $26.8[24.2,29.8]$ & $25.9[25.2,28.8]$ & 0.892 \\
\hline at end of surgery & $29.8[29.2,34.8]$ & $28.9[28.7,33.8]$ & 0.317 \\
\hline Blood glucose during $\mathrm{CPB}\left(\mathrm{mM} \cdot \mathrm{L}^{-1}\right)$ & $8.4[7.3,9.6]$ & $8.6[6.9,9.2]$ & 0.874 \\
\hline \multicolumn{4}{|l|}{$\operatorname{Cr}\left(y \mathrm{M} \cdot \mathrm{L}^{-1}\right)$} \\
\hline Baseline & $78[63,90]$ & $74[60,84]$ & 0.558 \\
\hline $6 \mathrm{~h}$ after the operation & $72[58.8,88]$ & $79[52,93]$ & 0.690 \\
\hline $24 \mathrm{~h}$ after the operation & $75[57,91]$ & $75[63,86]$ & 0.706 \\
\hline \multicolumn{4}{|l|}{$\mathrm{BUN}\left(\mathrm{mM} \cdot \mathrm{L}^{-1}\right)$} \\
\hline Baseline & $6.6[5.3,7.1]$ & $6.0[5.0,6.8]$ & 0.774 \\
\hline $6 \mathrm{~h}$ after the operation & $6.9[5.1,7.8]$ & $6.3[5.2,7.4]$ & 0.928 \\
\hline $24 \mathrm{~h}$ after the operation & $7.9[6.4,9.8]$ & $7.5[5.1,9.8]$ & 0.935 \\
\hline \multicolumn{4}{|l|}{ Urine volume (ml) } \\
\hline during $C P B$ & $300[200,600]$ & $600[300,800]$ & 0.086 \\
\hline $24 \mathrm{~h}$ after the operation & $2855[2700,3130]$ & $3010[2410,3330]$ & 0.589 \\
\hline \multicolumn{4}{|l|}{ Outcome data } \\
\hline Extubation time (h) & $17[17,18]$ & $11[6,16]$ & $0.042^{*}$ \\
\hline Length of stay in the ICU (h) & $43[42,68]$ & $36[19,43]$ & $0.008^{* *}$ \\
\hline Readmission within 30 days (n) & 0 & 0 & null \\
\hline Mortality in 1 year (\%) & 0 & 0 & null \\
\hline
\end{tabular}

*Statistically significant $\left({ }^{*} P<0.05{ }^{* *} P<0.01 * * * P 0.001\right)$. Norepinephrine and nitroglycerin during CPB are interventional factors for target blood pressure management. Abbreviations: CPB Cardiopulmonary bypass, MAP Mean arterial pressure, HCT Hematocrit, ICU Intensive care unit 
those in our research. This means that the longer surgery time, bypass time, and cross clamp time may be related to the postoperative lactate level. Compared with research showing that a high level of MAP during normothermic $\mathrm{CPB}$ does not reduce the risk of postoperative AKI and there is no difference in the peak of lactate postoperation [16], our study yielded different results for postoperative lactate levels when the temperature was $32-34^{\circ} \mathrm{C}$ during $\mathrm{CPB}$; this finding also implied that temperature correlates with lactate levels during the perioperative period. It has been reported that oxygen delivery inadequate to fulfill the metabolic needs of the patient is one of the factors promoting hyperlactatemia during $\mathrm{CPB}$, which is associated with reactive hyperglycemia that is probably due to insulin resistance triggered by catecholamine release [1]. In our study, blood glucose was controlled to $8 \mathrm{mM} \cdot \mathrm{L}^{-1}$ by insulin infusion during the perioperative period. Considering these factors, we further compared HR, MAP, HCT, blood glucose, Cr, BUN, surgery time, aortic occlusion time, $\mathrm{CPB}$ time and post-CPB time, finding no significant differences between the two groups.

Most current studies on how to maintain a safer MAP during $\mathrm{CPB}$ focus on the relationship between MAP and postoperative acute kidney injury (AKI) or cognitive dysfunction. Although there was no significant difference in postoperative cognitive dysfunction between the H-MAP group $(70-80 \mathrm{mmHg}$ ) and the L-MAP group $(40-50 \mathrm{mmHg})$ [17], maintaining a relatively high MAP level during $\mathrm{CPB}$ could effectively reduce the occurrence of AKI [18]. However, there were no significant differences in $\mathrm{Cr}$, BUN and urine volume between the two groups in this study, mainly because we targeted a MAP between 50 and $60 \mathrm{mmHg}$ in the L-MAP group instead of $40-50 \mathrm{mmHg}$. This result is consistent with the conclusion that maintaining a high MAP during $\mathrm{CPB}$ could improve perfusion.

We found that certain individual differences mattered much in target blood pressure management. Preoperative basic blood pressure and the antihypertensive drugs used by the patients should all be taken into consideration when performing blood pressure management precisely. On the other hand, many vasoconstrictors, such as epinephrine, could potentially bias the lactate value perioperatively. It has been reported that the median dose of epinephrine increased plasma lactate by $0.25 \mu \mathrm{g} / \mathrm{kg} /$ min, while dopamine had the opposite effect [19]. Norepinephrine usually does not induce an increase in the plasma lactate concentration [20]. In this study, vasoconstrictors were used only when necessary, and the dose of epinephrine used was less than $0.25 \mu \mathrm{g} / \mathrm{kg} / \mathrm{min}$ and had little effect on our results.

There are also some limitations in this study. For instance, this is a single center with a limited number of cases. Due to the small sample size, we compared the baseline of patients by absolute standardized difference scores (ASDs) [8]. We found that the ASDs of the two groups for the NYHAC (II/III), operation time, and post-CPB time were more than 0.5 , which indicated an imbalance between the two groups and may have introduced bias in the results. However, the ASDs of ASA (II/III) and LVEF (\%) were less than 0.5, and the ASDs of the aortic occlusion time and $\mathrm{CPB}$ time were less than 0.2 . Considering all of these factors, it was believed that such potential confounding factors may not have affected the results directly. Furthermore, all blood lancet levels increased significantly from post $\mathrm{CPB}$ until $6 \mathrm{~h}$ after the operation and were even more than $3 \mathrm{mM} \cdot \mathrm{L}^{-1}$ during that time. Therefore, multicenter, larger-sample studies are required in the future. Based on the finding that a relatively high MAP improved tissue perfusion during $\mathrm{CPB}$, our future study will monitor the peripheral circulation during CPB by ultrasound and calculate oxygen supply and consumption for more convincing evidence [21, 22].

\section{Conclusion}

Targeted MAP management between 70 and $80 \mathrm{mmHg}$ during $\mathrm{CPB}$ could better ameliorate the lactate level after cardiac surgery compared with MAPs between 50 and $60 \mathrm{mmHg}$. A relatively high blood pressure may be more conducive to improving tissue perfusion and oxygen supply, reducing the lactate level, and shortening the time of extubation and length of ICU stay, all of which are beneficial to cardiac surgery patients.

\section{Abbreviations}

CPB: Cardiopulmonary bypass; ICU: Intense care unit; NYHAC: New York Heart Association Class; BMI: Body mass index; LVEF: Left ventricular ejection fraction; ASA: American Society of Anesthesiologists; HR: Heart rate; HCT: Hematocrit; Cr: Creatinine; BUN: Blood urea nitrogen; MAP: Mean arterial pressure; AVR: Aortic valve replacement; AVP: Aortic valvuloplasty; MVR: Mitral valve replacement; MVP: Mitral valvuloplasty; TVP: Tricuspid valvuloplasty.

\section{Acknowledgments}

Not applicable.

\section{Authors' contributions}

J.W. and B.H. conceived and designed the clinical study; Q.M., L.S. and X.Ch performed the clinical study; D.W. and Zh.G. analyzed the data and drew graphs and tables; M.X. drafted this manuscript; and all authors approved the final manuscript.

\section{Funding}

This work was supported by the Shanghai Municipal Commission of Health Project (201840319), Shanghai Shen Kang Hospital Development Center Project (SHDC2020CR4063) and Medical Engineering Cross Research Fund of Jiaotong University Star Program of Shanghai Jiaotong University (YG2021QN124).

\section{Availability of data and materials}

The datasets used and/or analyzed during the current study are available from the corresponding author on reasonable request. 


\section{Declarations}

\section{Ethics approval and consent to participate}

Written informed consent was obtained from all participants. The study was approved by the Shanghai Chest Hospital of Shanghai Jiaotong University research ethics board (KS1960) at 31/10/2019 and conducted in accordance with the Declaration of Helsinki tenets and the Basel. This trial was registered at the Chinese Clinical Trial Center on 8/1/2020 with the registration number ChiCTR2000028941 (http://www.chictr.org.cn/index.aspx).

\section{Consent for publication}

All authors agree for publication.

\section{Competing interests}

The authors declare that they have no competing interests.

\section{Author details}

'Department of Anesthesiology, Shanghai Chest Hospital, Shanghai Jiao Tong University, No. 241 West Huaihai Road, Shanghai 200030, China. ${ }^{2}$ Department of Cardiopulmonary Bypass, Shanghai Chest Hospital, Shanghai Jiao Tong University, Shanghai, China. ${ }^{3}$ Department of Intensive Care Unit, Shanghai Chest Hospital, Shanghai Jiao Tong University, Shanghai, China.

Received: 20 June 2021 Accepted: 1 December 2021

Published online: 08 December 2021

\section{References}

1. Ranucci M, De Toffol B, Isgrò G, Romitti F, Conti D, Vicentini M. Hyperlactatemia during cardiopulmonary bypass: determinants and impact on postoperative outcome. Crit Care. 2006;10:R167.

2. Minton J, Sidebotham DA. Hyperlactatemia and cardiac surgery. J Extra Corpor Technol. 2017;49:7-15.

3. Govender P, Tosh W, Burt C, Falter F. Evaluation of increase in intraoperative lactate level as a predictor of outcome in adults after cardiac surgery. J Cardiothorac Vasc Anesth. 2020;34:877-84.

4. Matteucci M, Ferrarese S, Cantore C, Cappabianca G, Massimi G, Mantovani $\mathrm{V}$, et al. Hyperlactatemia during cardiopulmonary bypass: risk factors and impact on surgical results with a focus on the long-term outcome. Perfusion. 2020:35:756-62.

5. Wahba A, Milojevic M, Boer C, De Somer F, Gudbjartsson T, van den Goor J, et al. 2019 EACTS/EACTA/EBCP guidelines on cardiopulmonary bypass in adult cardiac surgery. Eur J Cardiothorac Surg. 2020;57:210-51.

6. Vedel AG, Holmgaard F, Rasmussen LS, Langkilde A, Paulson OB, Lange T, et al. High-target versus low-target blood pressure management during cardiopulmonary bypass to prevent cerebral injury in cardiac surgery patients: a randomized controlled trial. Circulation. 2018;137:1770-80.

7. Maheshwari K, Khanna S, Bajracharya GR, Makarova N, Riter Q, Raza S, et al. A randomized trial of continuous noninvasive blood pressure monitoring during noncardiac surgery. Anesth Analg. 2018;127:424-31.

8. Austin PC. Balance diagnostics for comparing the distribution of baseline covariates between treatment groups in propensity-score matched samples. Stat Med. 2009;28:3083-107.

9. Kapoor P, Mandal B, Chowdhury U, Singh S, Kiran U. Changes in myocardial lactate, pyruvate and lactate-pyruvate ratio during cardiopulmonary bypass for elective adult cardiac surgery: early indicator of morbidity. J Anaesthesiol Clin Pharmacol. 2011;27:225-32.

10. Sturm T, Leiblein J, Schneider-Lindner $V$, Kirschning T, Thiel M. Association of microcirculation, macrocirculation, and severity of illness in septic shock: a prospective observational study to identify microcirculatory targets potentially suitable for guidance of hemodynamic therapy. J Intensive Care Med. 2018:33:256-66.

11. Song Y, Soh S, Shim JK, Park KU, Kwak YL. Skin perfusion pressure as an indicator of tissue perfusion in valvular heart surgery: preliminary results from a prospective, observational study. PLoS One. 2017;12:e0184555.

12. Kędziora A, Wierzbicki K, Piątek J, Hymczak H, Górkiewicz-Kot I, Milaniak I, et al. Postoperative hyperlactatemia and serum lactate level trends among heart transplant recipients. Peer J. 2020;8:e8334.
13. Darocha T, Podsiadło P, Polak M, Hymczak H, Krzych Ł, Skalski J, et al. Prognostic factors for nonasphyxia-related cardiac arrest patients undergoing extracorporeal rewarming - HELP registry study. J Cardiothorac Vasc Anesth. 2020;34:365-71

14. Siepe M, Pfeiffer T, Gieringer A, Zemann S, Benk C, Schlensak C, et al. Increased systemic perfusion pressure during cardiopulmonary bypass is associated with less early postoperative cognitive dysfunction and delirium. Eur J Cardiothorac Surg. 2011;40:200-7.

15. Gold JP, Charlson ME, Williams-Russo P, Szatrowski TP, Peterson JC, Pirraglia PA, et al. Improvement of outcomes after coronary artery bypass. A randomized trial comparing intraoperative high versus low mean arterial pressure. J Thorac Cardiovasc Surg. 1995;110:1302-11.

16. Azau A, Markowicz P, Corbeau JJ, Cottineau C, Moreau X, Baufreton C, et al. Increasing mean arterial pressure during cardiac surgery does not reduce the rate of postoperative acute kidney injury. Perfusion. 2014;29:496-504

17. Hori D, Max L, Laflam A, Brown C, Neufeld KJ, Adachi H, et al. Blood pressure deviations from optimal mean arterial pressure during cardiac surgery measured with a novel monitor of cerebral blood flow and risk for perioperative delirium: a pilot study. J Cardiothorac Vasc Anesth. 2016;30:606-12.

18. Kanji HD, Schulze CJ, Hervas-Malo M, Wang P, Ross DB, Zibdawi M, et al. Difference between pre-operative and cardiopulmonary bypass mean arterial pressure is independently associated with early cardiac surgeryassociated acute kidney injury. J Cardiothorac Surg. 2010;5:71.

19. Day NP, Phu NH, Bethell DP, Mai NT, Chau TT, Hien TT, et al. The effects of dopamine and adrenaline infusions on acid-base balance and systemic haemodynamics in severe infection. Lancet. 1996;348:219-23.

20. Ensinger H, Geisser W, Brinkmann A, Wachter U, Vogt J, Radermacher P, et al. Metabolic effects of norepinephrine and dobutamine in healthy volunteers. Shock. 2002;18:495-500.

21. Themelin N, Biston P, Massart J, Lelubre C, Piagnerelli M. Effects of red blood cell transfusion on global oxygenation in anemic critically ill patients. Transfusion. 2021;61:1071-9.

22. de Somer F, Mulholland JW, Bryan MR, Aloisio T, Van Nooten GJ, Ranucc M. O2 delivery and $\mathrm{CO} 2$ production during cardiopulmonary bypass as determinants of acute kidney injury: time for a goal-directed perfusion management? Crit Care. 2011;15:R192.

\section{Publisher's Note}

Springer Nature remains neutral with regard to jurisdictional claims in published maps and institutional affiliations.

Ready to submit your research? Choose BMC and benefit from

- fast, convenient online submission

- thorough peer review by experienced researchers in your field

- rapid publication on acceptance

- support for research data, including large and complex data types

- gold Open Access which fosters wider collaboration and increased citations

- maximum visibility for your research: over 100M website views per year

At $\mathrm{BMC}$, research is always in progress.

Learn more biomedcentral.com/submissions 